\title{
Five case reports on treatment of diabetes by Artemisia annua and Artemisia afra herbal tea
}

\begin{abstract}
Results registered for five cases in the province of Maniema, RDCongo document for the first time on a scientific and medical basis the antidiabetic effect of Artemisia herbal tea. This happened in the context of large scale clinical trials with Artemisia annua and Artemisia afra herbal tea, trials which successfully documented the efficacy of these plants against malaria and schistosomiasis, as well as other beneficial health effects.
\end{abstract}

Volume 8 Issue 2 - 2020

\author{
Jérôme Munyangi,' Michel Idumbo, ${ }^{2}$ Bavon \\ Mupenda, ${ }^{3}$ Pierre Lutgen ${ }^{4}$ \\ 'Faculté de Médecine,Université de Kolwezi, Democratic \\ Republic of the Congo \\ ${ }^{2}$ Centre de Santé de Lubile, Maniema, Democratic Republic of \\ the Congo \\ ${ }^{3}$ Ecole de Santé Publique Université de Kinshasa, Democratic \\ Republic of the Congo \\ ${ }^{4}$ IFBV-BELHERB, Luxembourg
}

Correspondence: Pierre Lutgen, IFBV-BELHERB, L-6988,

Hostert, Luxembourg, Email lutgenp@gmail.com

Received: February II, 2020 | Published: April 06, 2020

\section{Introduction}

Diabetes burden is rising sharply in Africa. WHO forecasts in the African region an increase from a total of 7.020.000 cases in the year 2000 to 18.234 .000 in 2030 (See annex I for details per country). Similar data are quoted by other studies. ${ }^{1}$ Children and adolescents account for almost half of all newly diagnosed cases of type 2 diabetes. And the death toll due to this disease is raising dramatically. Diabetes is a leading cause of blindness, amputation, kidney failure and heart disease. An effect which is less known and studied is the impact on malaria. ${ }^{2}$ Africa not only has to fight transmittable diseases but the burden of non-transmittable diseases will also sharply increase.

People suffering from mild diabetes can keep their disease under control by an appropriate diet. If it becomes more severe insulin and/ or drugs against blood sugar must be administred. Most of these drugs however are the cause of severe side effects. Traditional and herbal medicines against diabetes have been widely used in the past and are still to-day. Research on these alternative medicines becomes urgent and unavaidable for Africa.We reported previously on clinical trials we successfully completed in the province of Maniema, RDCongo, with Artemisia herbal tea against malaria and schistosomiasis., During these trials we noticed that several patients suffered from diabetes. They had fasting blood sugar levels of 180 to $280 \mathrm{mg} / \mathrm{ml}$. In five of these cases we noticed a remarkable alleviation of their disease and we made a close medical follow-up, including blood analysis, anthropometric measurements, records on renal and hepatic functions before, during and after treatment with Artemisia annua and Artemisia afra aqueous infusions.

The first case which aroused our interest in the potential impact of Artemisia herbal tea was a lady of 40 years of age. During the preliminary interviews and checks for the Artemisia trials we noticed that she had problems with polyurea, polydipsia and weight loss. Her fasting blood sugar (FBS) was at $250 \mathrm{mg} / \mathrm{ml}$ and the postprandial one at $275 \mathrm{mg} / \mathrm{ml}$. After the therapeutic treatment of 7 days with $5 \mathrm{~g} / \mathrm{l}$ of dried leaves and twigs per day, we noticed that her bloog sugar had decreased to $180 \mathrm{mg} / \mathrm{ml}$. We decided to continue the treatment. 14 days later all symptoms of her diabetes had vanished, despite she lived on a normal diet. Fasting blood sugar was at $110 \mathrm{mg} / \mathrm{ml}$ and the postprandial one at $130 \mathrm{mg} / \mathrm{ml}$. We continued the herbal treatment for two months at a dose of $5 \mathrm{~g} / \mathrm{L} 3 \mathrm{x}$ per week. Six months later glycemia values stayed normal and stable, despite a normal diet and without drugs. This success story motivated to run a prospective Artemisia annua and Artemisia afra pilot study with five patients suffering simultaneously from diabetes and malaria, and keeping an eye on side effects.

\section{Materials and methods}

\section{Materials}

We used the same Artemisia annua and Artemisia afra from Senegal, Burundi and Luxembourg as those in the clinical trials for malaria and schistosomiasis (op.cit). The samples were analyzed at the Worcester Polytechnic Institute.

\section{Preparation of the Artemisia herbal tea}

$5 \mathrm{~g}$ of dried twigs and leaves of Artemisia annua or Artemisia afra are added to a liter of tap water boiling at $100^{\circ} \mathrm{C}$. The recipient is removed from the fire and the herb is left to infuse during 15 minutes. The objective was to treat malaria infected patients at the daily dose of $1 \mathrm{~L}$ of this type of infusion during 7 days. For the patients selected for the diabetes-malaria study this same treatment was prolongated during two weeks and after the treatment was reduced to the daily dose of $5 \mathrm{~g} / \mathrm{L} 3 \mathrm{x}$ per week during 2 months. Each one of these patients was followed by a thorough medical examination by a medical doctor including the required laboraory analyses. This included the following parameters: body weight, blood pressure, blood analysis, renal and hepatic functions. These parameters were measured on day one of the herbal treatment and then repateated every week.

Each patient was asked to describe the effects he ressented during the treatment,like headache, menstrual problems, dizziness, fatigue, palpitations, vomiting, diarrhea, skin eruptions. At the start of the trial patients with serious renal, hepatic, gastro-intestinal or cardiovascular problems were excluded.Each patient was explained in detail the purpose of this herbal treatment. 


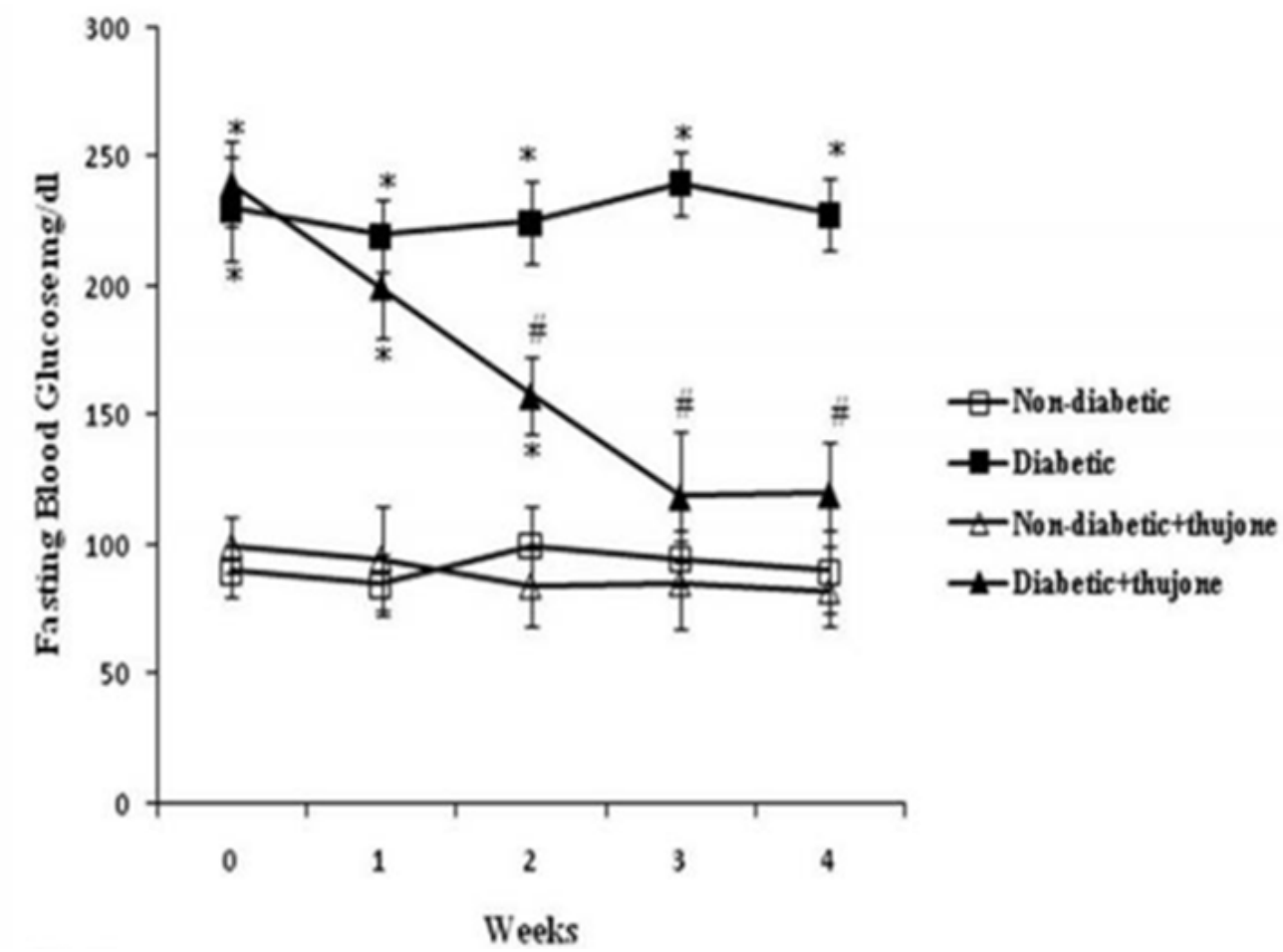

Figure I Effect of thujone treatment (4 weeks) on plasma glucose levels. Values are means $\pm S E(n=6)$.

*Significantly different from non-diabetic $(\mathrm{p}<0.05)$.

\#Significantly different from diabetic $(p<0.05)$.

"This figure is an excerpt of ref 53 "

\section{Results}

Case 1: Male, 50 years old, married, two children, suffering from diabetes since 5 years. As treatment for his diabetes to lower blood sugar he used oral Daonil at the dose of 4 daily tablets of $5 \mathrm{mg}$ each and adapted his diet. One year before our clinical trial his diabetes aggravated and he was admitted to hospital for a treatment by insulin injections at the dose of 40 I.U twice a day. At the start of his participation in our clinical trial his body temperature was at $38.8^{\circ} \mathrm{C}$, his heart rate at 100 beats $/ \mathrm{min}$, his blood pressure $120 / 70 \mathrm{~mm} / \mathrm{Hg}$, his respiration rate $18 / \mathrm{min}$. The paraclinic tests gave the following results: the rapid malaria diagnostic test (RDT) was positive,fasting glycemia at $250 \mathrm{mg} / \mathrm{dL}$, parasitemia at 8000 trophozoites $/ \mathrm{mm}^{3}$ in blood smear, the transaminases ASAT at 60 I.U./L and 50 I.U./L, creatinin at $80 \mu \mathrm{mol} / \mathrm{L}$.

The patient was treated by Artemisia annua infusions at the dose of $5 \mathrm{~g} / \mathrm{L}, 3$ times per day during 7 days, simultaneously with his sugar lowering drug. After 7 days of treatment fever had disappeared, glycemia was at $190 \mathrm{mg} / \mathrm{dL}$. 14 days later glycemia had lowered to $140 \mathrm{mg} / \mathrm{L}$, Symptoms of polyurea, polydipsia and fatigue had vanished. We continued the Artemisia annua treatment for 2 months and this decreased the glycemia to $110 \mathrm{mg} / \mathrm{dL}$, with no signs of relapse. His diet had become the standard of his community and he had reduced the dose of Daonil tablets from 4 to 2 per day. 6 months later his blood sugar stayed normal without the need of pharmaceutical drugs. The transaminases ASAT and ALAT were now 30 I.U./L and 35 I.U./L. At the start of the clinical trial the patient suffered from nausea and dizziness.

Case 2: Male, 45, suffering from diabetes since 10 months, treated with oral hypoglycemic Daonil at the dose of 4 daily tablets of $5 \mathrm{mg}$.
At the admission to our clinical trial his fasting glycemia was $270 \mathrm{mg} /$ $\mathrm{dL}$ and postprandial glycemia $300 \mathrm{mg} / \mathrm{dL}$. But the patient confessed that he has stopped his Daonil treatment for 4 weeks because he could not afford paying for it. His body temperature was at $38.5^{\circ} \mathrm{C}$. The immunochromatographic rapid diagnostic test (RDT) was positive. The blood smear gave a parasitemia of 10000 trophozoites $/ \mathrm{mm}^{3}$. ASAT was 45 I.U./L, ALAT 55 I.U./L, urea, $11 \mathrm{mmol} / \mathrm{L}$ creatinine $80 \mu \mathrm{mol} / \mathrm{L}$. Malaria was treated at a daily dose of $5 \mathrm{~g} / \mathrm{L}$ of Artemisia afra herbal tea per day simultaneously with Daonil. After one week his parasitemia had decreased to $130 \mathrm{mg} / \mathrm{dL}$ and all diabetic symptoms improved. The herbal tea consequently was lowered to $5 \mathrm{~g} / \mathrm{L} 3 \mathrm{x}$ par week. After 14 days blood glucose was at $120 \mathrm{mg} / \mathrm{dl}$. 2 months later his blood glucose stabilized at $110 / \mathrm{mg} / \mathrm{dl}$, with a normal diet and without Daonil. Transaminase levels were 30 IU/L for ASAT and $28 \mathrm{IU} / \mathrm{L}$ for ALAT.The health effects which had been reported were headache, nausea and vomiting.

Case 3: Female, 35 years of age, weighing $75 \mathrm{~kg}$ and $150 \mathrm{~cm}$ tall. Body mass index (BMI) 33.3, slightly obese (grade 1). Her fasting sugar glucose was $275 \mathrm{mg} / \mathrm{ml}$ and the postprandial one of $300 \mathrm{mg} /$ $\mathrm{ml}$. She was not aware of her diabetes.Her fever was at $38.8^{\circ} \mathrm{C}$, her heart rate at 105 beats $/ \mathrm{min}$, the blood pressure at $140 / 60 \mathrm{~mm} \mathrm{Hg}$, her respiration rate $18 / \mathrm{min}$. The immunochromatographic rapid diagnostic test (RDT) was positive, for parasitemia 7000 trophozoites were found in the blood smear. ASAT 30 I.U./L, ALAT 28 I.U./L, urea $11 \mathrm{mmol} / \mathrm{L}$, creatinine $110 \mu \mathrm{mol} / \mathrm{L}$. She was treated with Artemisia afra herbal tea $5 \mathrm{~g} / \mathrm{L}$ during 14 days, without any hypoglycemic drug in parallel, but with the recommandation of an improved diet against diabetes. Her blood sugar decreased to $170 \mathrm{mg} / \mathrm{dL}$. The treatment was continued for 2 months at the dose of $5 \mathrm{~g} 3 \mathrm{x}$ per week. Diabetic symptoms improved and fasting blood sugar stabilized at $120 \mathrm{mg} / \mathrm{dL}$. The patient reported secondary effects like palpitations, dizziness, nausea. 
Table I Partial phytochemical composition of Artemisia cultivates used in this study (mg/g DW)

\begin{tabular}{|c|c|c|c|c|c|}
\hline Phytochemical & A. afra PAR & SEN & I:4 Blend & A. annua LUX & BUR \\
\hline Voucher Id & $\begin{array}{l}\text { LG00I9528 } \\
\text { Universite de Liege }\end{array}$ & $\begin{array}{l}\text { LG00 I } 9529 \text { Universite } \\
\text { de Liege }\end{array}$ & Not applicable & $\begin{array}{l}\text { MNHNLI } 7732 \\
\text { Herbarium Luxembourg }\end{array}$ & $\begin{array}{l}\text { LG00I } 9527 \\
\text { Universite de Liege }\end{array}$ \\
\hline \multicolumn{6}{|c|}{ Total terpenoids ${ }^{\mathrm{a}}$ and flavonoids ${ }^{\mathrm{b}}$} \\
\hline Total terpenoids & $47.92 \mathrm{a}$ & $31.94 a$ & 35.14 & $63.89 x$ & $45.14 x$ \\
\hline Total flavonoids & $3.74 a$ & $3.03 b$ & 3.18 & $5.55 x$ & $3.84 y$ \\
\hline \multicolumn{6}{|l|}{ Artemisinic compounds } \\
\hline Artemisinin & nd & 0.045 & 0.036 & $1.34 \mathrm{x}$ & $1.70 y$ \\
\hline Arteannuin B & nd & nd & nd & 0.93 & nd \\
\hline Deoxyartemisinin & nd & nd & nd & $0.32 x$ & $0.39 y$ \\
\hline Artemisinic acid & nd & nd & nd & 0.86 & nd \\
\hline \multicolumn{6}{|l|}{ Flavonoids } \\
\hline Luteolin & $0.07 a$ & $0.1 \mathrm{la}$ & 0.11 & 0.07 & nd \\
\hline \multicolumn{6}{|l|}{ Phenolic acids } \\
\hline Cholorogenic acid & $0.45 a$ & $2.36 \mathrm{~b}$ & 1.98 & $1.32 x$ & $0.09 y$ \\
\hline Rosmarinic acid & nd & nd & nd & nd & nd \\
\hline \multicolumn{6}{|l|}{ Coumarins } \\
\hline Scopoletin & $0.10 \mathrm{a}$ & $0.10 \mathrm{a}$ & 0.1 & $0.06 x$ & $0.05 x$ \\
\hline \multicolumn{6}{|l|}{ Essential oils } \\
\hline Camphor & $3.26 a$ & $0.72 b$ & 1.24 & $0.44 x$ & $0.33 y$ \\
\hline Caryophyllene $^{c}$ & nd & nd & nd & nd & nd \\
\hline$\beta$-pinene ${ }^{c}$ & nd & nd & nd & nd & nd \\
\hline I,8 cineole (eucalyptol) & $0.47 \mathrm{a}$ & $0.27 \mathrm{~b}$ & 0.31 & 0.03 & nd \\
\hline Borneol $^{c}$ & $0.67 \mathrm{a}$ & $0.07 b$ & 0.19 & nd & nd \\
\hline Spathulenol ${ }^{\mathrm{c}}$ & 0.12 & nd & 0.02 & nd & nd \\
\hline$\beta$-neoclovene ${ }^{c}$ & $0.5 \mathrm{la}$ & $0.13 b$ & 0.21 & nd & nd \\
\hline Phytol $^{c}$ & nd & nd & nd & $0.40 x$ & $0.68 y$ \\
\hline Thujone $^{c}$ & nd & 0.86 & 0.69 & nd & nd \\
\hline
\end{tabular}

Plant cultivator origins (BUR, Burundi; LUX, Luxembourg; PAR, Paris; SEN, Senegal) had an $n>4$. Significance at P<0.05; a,b letters compare A. afra PAR and SEN; $x, y$ compares A. annua LUX and BUR; nd, not detectable. Statistical analysis impossible when I of the 2 samples was nd

${ }^{a}$ Expressed as santonin equivalents

${ }^{b}$ Expressed as quercetin equivalents

'Expressed as camphor equivalents

Case 4: Female, 36 years of age. Was aware of her diabetes since 2 years. Despite the use of an antiglycemic drug and diet restrictions, her fasting sugar glucose was at $265 \mathrm{mg} / \mathrm{mL}$. Body temperature $37.5^{\circ} \mathrm{C}$, heart rate at 70 beats/minute, blood pressure $120 / 70 \mathrm{mmHg}$, respiratory rate $17 / \mathrm{min}$, RDT negative, parasitemia of $1000 / \mathrm{mm}^{3}$ trophozoites in blood smear, ASAT 30 I.U./L, ALAT 28 I.U./L, urea $11 \mathrm{mmmol} / \mathrm{L}$, creatinine $100 \mu \mathrm{mol} / \mathrm{L}$. We applied a treatment of Artemisia anпиa herbal tea $5 \mathrm{~g} / \mathrm{L}$ during 14 days simultaneously with her antidiabetic drug. Blood sugar decreased to $160 \mathrm{mg} / \mathrm{dL}$. Afterwards only the herbal tea was administred for 2 months. Her blood glucose stabilized at $130 \mathrm{mg} / \mathrm{mL}$, her polyuria and polydipsia disappeared and she had gained some weight. Since that date she completely stopped the antidiabetic drug and lives on a normal diet. The patient had reported dizziness and nausea.

Case 5: Male, 31 years of age. He was found to be diabetic in a clinical analysis 2 years before. He was living on a diet low in calories and he used Daonil for his treatment. At the start of our clinical trials his fasting glucose was at $180 \mathrm{mg} 7 \mathrm{dL}$ and the postprandial one at 225 $\mathrm{mg} / \mathrm{dL}$. His body temperature was normal, his heart rate at 70 beats/ 
minure, blood pressure $130 / 70 \mathrm{mmHg}$, the respiratory rate at $16 / \mathrm{min}$, RDT negative, no parasites in blood smear, ASAT 40 I.U./L, ALAT 30 I.U./L, urea $12 \mathrm{mmol} / \mathrm{L}$, creatinin $90 \mu \mathrm{mol} / \mathrm{L}$. We adminstred Artemisia annua herbal tea for fourteen days at a dose of $5 \mathrm{~g} / \mathrm{L} 3 \mathrm{x} /$ day and he continued his diet low in calories. His fasting blood glucose decreased to $110 \mathrm{mg} / \mathrm{dL}$ and the postprandial one to $130 \mathrm{mg} / \mathrm{dL}$. We continued the Artemisia annua treatment for 2 months at a dose of $5 \mathrm{~g} / \mathrm{L} 3 \mathrm{x}$ per weeek.His blood sugar stabilized at $110 \mathrm{mg} / \mathrm{dL}$ and he had returned to a standard diet. No secondary effect was observed.

Addtional remark: For patients of case1.and 2.we found high levels of ALAT and ASAT. It is known that diabetes raises these levels. The administration of Artemisia herbal tea signifactly lowered these values and confirms the hepatoprotective efficiency of Artemisias. This hepatoprotective properties had also been observed at the Université des Montagnes in Cameroon for Artemisia annua. ${ }^{5}$ But pure artemisinin significantly raises ALAT and ASAT. ${ }^{6}$

\section{Artemisia plants and diabetes}

In the large family of Artemisia plants, Artemisia annua (L.) is the best known, it is part the the Chinese Pharmacopeia and has widely been used against fever, malaria and other diseases. Artemisia afra (Jacq) is known in the African Pharmacopeia, for the treatment of diseases like coughing, rhinitis, headache, dyspepsia, intestinal problems, malaria, diabetes, renal problems.It was surprising to find in our trial similar antidiabetic results for both Artemisia annua and Artemisia afra. All Artemisia species seem to have a hypoglycemic effect, despite the absence of artemisinin in the latter.Trials and results on animals have been reported earlier.Treatment of rats with Artemisia annua aqueous extract reduced the serum glucose after 4 weeks from 110 to $70 \mathrm{mg} / \mathrm{mL} .^{7-17} \mathrm{An}$ excellent review paper has been published in Ethiopia. Some 14 studies clearly showed that both the aqueous and alcoholic extracts of several species of Artemisia produced significant hypoglycemic effects. ${ }^{18}$

Artemisia plants are used in many countries as traditional remedy against diabetes, but in vivo trials on humans are scarce. In 1986, in Morocco, fifteen patients with diabetes mellitus were treated with Artemisia herba-alba extract. Results showed that the extract caused considerable lowering of elevated blood sugar and 14 out of 15 patients had good remission of diabetic symptoms. But meanwhile it has been recognized that lyophilized extracts of Artemisia are not stable and rapidly lose their properties through evaporation and oxidation. ${ }^{19}$ Trials made in Senegal in 2016 by a partner of IFBVBELHERB and MfL(unpublished results, P.Lutgen) indicated that a 14 day consumption of Artemisia annua infusion (100g/person) gives a $15-20 \%$ reduction in glycemia.In fact, the results reported in the present paper and gathered in RDCongo in five cases document for the first time on a scientific and medical basis the antidiabetic effect of Artemisia herbal tea.

\section{Potentiel constituents responsible for the antidiabetic properties of Artemisia plants}

Flavonoids and essential oils only have a minor impact and their role is controversial. It is difficult to find scientific papers on this subject.

The question concerning artemisinin and derivatives is crucial. They inhibit and even cause the apoptosis of $\beta$-cells, like other peroxides do. These pancreatic cells are essential for the generation and efficiency of insulin. The consumption of ACTs comcommittant with Artemisia herbal tea could thus enhance the diabetes of the patients. The results of research in China showed that artemisinin and dihydroartemisin in significantly increased the apoptosis of $\beta$-cells induced by palmitic acid. ${ }^{20}$ Worse even, a flurry of publicity appeared recently on internet, proposing the sales of artemisinin and derivatives as drugs against diabetes. They refered to a paper published in 2017 in the journal Cell, where a European consortium reported that artemether could convert $\alpha$-cells into $\beta$-cells. A recent indepth study refuted using anti-malarial drug to treat diabetes. They even found or confirmed that artemether abrogates $\beta$-cell insulin secretion in response to glucose. ${ }^{21}$ Artemisinin drugs also augment cytochrome CYP3A4, which will accelerate the metabolism of any drug, be it pharmaceutical or natural. ${ }^{22,23}$

Arachidonic acid however increases insulin secretion and the sensitivity to insulin. This had been extensively described in assays with animals. The effect has been confirmed in humans. It acts as an inhibitor of enzymes which induce human $\beta$-cell destruction. Arachidonic acidis an extremely important fatty acid involved in cell regulation. It is a polyunsaturated fatty acid $(20: 4 \mathrm{n} 6){ }^{24-27}$ Arachidonic acid is present in red meat, eggs; 0.1 in fatty meat, 0.7 in fish oil, $0.3 \%$ in eggs, $0.4 \%$ of the total fat of breast milk, traces in cow milk. Higher plants and vegetables do not produce or contain arachidonic acid. It is only found and extracted from mosses and algae. A phytochemical analysis of five Artemisia species in Turkey shows that saturated fatty acids in these plants represent on the average $40 \%$ of the total and the unsaturated fatty acids $60 \%$, including those with antimalarial activities like linoleic acid, arachidonic acid and linolenic acid. The real surprise is that based on the total fatty acid content Artemisia armeniaca contains $6.47 \%$ arachidonic acid, $A$ incana $7.79 \%, A$ tournefortiana $2.61 \%$, A hausknechtii $7.44 \%$ A scoparia $3.17 \%$. This is ten times higher than in meat, eggs or fish oil. And it is possibly related to the prophylactic and therapeutic properties of all Artemisia plants. $^{28,29}$

Anthocyanins and proanthocyanidins (condensed tannins) also are able to protect and regenerate $\beta$-cells. ${ }^{30,31}$

The fact that mostly aqueous or ethanolic extracts have an antidiabetic impact points to polar rather than to lipohilic constituents of the Artemisia plants. Recent publications confirm this hypothesis and the major apolar contribution stems from proanthocyanidins (condensed tannins). ${ }^{32}$ Plants rich in proanthocyanidins like neem, cinnamon, grape seed or peel, sorghum, pomegranate peel, apple, blueberry all have a strong antidiabetic effect.

The consumption of whole fruits, particularly blueberries, grapes, and apples, is significantly associated with a lower risk of type 2 diabetes, whereas consumption of fruit juice barely has an effect. This confirms the proanthocyanidin hypothesis. Grape skins are rich in proanthocyanidins and the latter are absent in grape juice. ${ }^{33}$

Artemisia plants are rich in proanthocyanidins. A very recent paper deals with Artemisia herba alba and finds a concentration of 2100 $\mathrm{mg} / 100 \mathrm{~g} .{ }^{34}$ Another paper detected the presence of anthocyanidins and tannins in several Artemisia species in Iran without quantifying them: A. absinthium, A. annua, A. biennis, A. diffusa, A santolina, A turanica, A. vulgaris, A. sieberi. ${ }^{35,36}$

Another molecule which has been studied extensively for its antidiabetic properties is arginine. Experiments conducted by researchers from the University of Copenhagen show that the amino acid arginine-found in a wide variety of foods such as salmon, eggs and nuts-greatly improves the body's ability to metabolize glucose. Arginine stimulates a hormone linked to the treatment of type 2 diabetes, and works just as well as several established drugs on the market. ${ }^{37}$ In fact, already in 1966 the University of Michigan had found that the intravenous administration of amino-acids to healthy subjects, either as mixtures or individually, stimulated the release of insulin. The most effective stimulus was by arginine given alone. ${ }^{38}$ In 1998 a study from India showed that the action of arginine is related to the production of nitric oxide..$^{39}$ Medicinal herbs like Artemisia annua or Artemisia maritima are very rich in nitrates and arginine.

A recent study from Ukraine has analyzed the amino acid content in some 8 Artemisia plants of this subgenus and found that they are all 5 to 10 times richer in arginine than other herbs or vegetables, with $A$ annua top-ranking $(2 \mathrm{~g} / 100 \mathrm{~g}){ }^{40}$ Recent evidence suggests that the 
supposedly inert anions nitrate and nitrite are metabolized in blood and tissues to form nitric oxide $\mathrm{NO}$ and other bioactive nitrogen oxides. These stimulate pancreatic Langerhans islet function and subsequent insulin formation in vivo. ${ }^{41}$ There is a growing body of evidence that glucose ingestion causes a number of pro-inflammatory changes in normal as well as diabetic humans. Glucose stimulates the endothelial production of the pro-inflammatory Interleukin- $8 .{ }^{42}$ This has also been described by a research team in Palestine. ${ }^{43,44}$

Chlorogenic acid and other caffeoylquinic acids also have antidiabetic properties. A study on Artemisia argyi led to the successful identification of caffeoylquinic acids as active constituents. ${ }^{45,46}$

Polysaccharides seem to have an effect. They inhibit the intestinal absorption of glucose. They also alleviate $\beta$-cell dysfunction. ${ }^{47,48}$

Pentacyclic triterpenes also have an antidiabetic effect. ${ }^{49,50}$

Saponins deserve more research. ${ }^{51,52}$

In the case of Artemisia plants rich in thujone like Artemisia afra, herba alba, absinthium, arborescens, thujone probably plays a major role. $^{53}$

Sulfur present in Artemisias may also play an important role. $\mathrm{H}_{2} \mathrm{~S}$ has the reputation to be a toxic gas. But at low concentrations it has beneficial health effects and cures several diseases. Most of the balneary tradition is based on the presence of hydrogen sulfide in some mineral waters. The effect may be related to the precipitation of excess iron in the form of insoluble FeS. In their major analytical work Brisibe and Ferreira find that Artemisia annua contains $0.3 \%$ of sulfur. But only $0.1 \%$ in the majority of other plant leaves. ${ }^{54}$ Among medicinal plants Artemisia annua is the richest in potassium (Brisibe et al., op.cit). Some studies have found low-normal potassium to be associated with increased diabetes risk. In a recent multi-ethnic cohort study, a significant inverse association between serum $\mathrm{K}$ and fasting glucose was found, but no significant association with longer-term diabetes risk. The authors conclude that this needs further studies. ${ }^{55}$

\section{Conclusion}

Our findings show that Artemisia annua and Artemisia afra herbal infusions have an high therapeutic efficacy in the treatment of diabetes. In fact these results gathered in RD Congo in five cases document for the first time on a scientific and medical basis the antidiabetic effect of Artemisia herbal tea in humans. Blood sugar could be lowered to standard levels. This confirms previous trials on animals. This antidiabetic property of Artemisia aqueous infusions is a polytherapy where various constituents of the plant work in synergy. No side effects or toxicities were observed in our trials. We recognize that further assays are needed to confirm our observations and better define the rôle of the constituents. Ideally a large scale double blind clinical trial is recommended. This would help to better understand the mechanisms involved and the precautions to be taken to avoid treatment failures.

\section{Acknowledgments}

We acknowledge with gratitude the support of La Maison de l'Artemisia, France, Worcester Polytechnic Institute, USA, Université de Liège, Belgium, Mother Nature, Burundi and Association IFBVBELHERB, Luxembourg. The findings and cases we report in this scientific paper might be due to serendipity, but they were probably inspired by previous work in this field in Palestine, Cameroon, Luxembourg and Senegal.

\section{Conflicts of interest}

We declare that there are no conflicts of interest.

\section{ANNEX I}

\section{WHO African Region}

Diabetes in the WHO African Region

\begin{tabular}{|c|c|c|}
\hline Country & 2000 & 2030 \\
\hline Algeria & $4,26,000$ & $12,03,000$ \\
\hline Angola & 51,000 & $1,40,000$ \\
\hline Benin & 87,000 & $2,66,000$ \\
\hline Botswana & 25,000 & 45,000 \\
\hline Burkina Faso & $1,24,000$ & $3,88,000$ \\
\hline Burundi & 26,000 & 72,000 \\
\hline Cameroon & 70,000 & I,7I,000 \\
\hline Cape Verde & 7,000 & 24,000 \\
\hline Central African Republic & 18,000 & 38,000 \\
\hline Chad & 97,000 & $2,69,000$ \\
\hline Comoros & 4,000 & 15,000 \\
\hline Congo & 14,000 & 39,000 \\
\hline Côte d'Ivoire & $2,64,000$ & $6,36,000$ \\
\hline $\begin{array}{l}\text { Democratic Republic of the } \\
\text { Congo }\end{array}$ & $2,91,000$ & $9,10,000$ \\
\hline Equatorial Guinea & 8,000 & 21,000 \\
\hline Eritrea & 47,000 & $1,42,000$ \\
\hline Ethiopia & $7,96,000$ & $18,20,000$ \\
\hline Gabon & 8,000 & 14,000 \\
\hline Gambia & 22,000 & 61,000 \\
\hline Ghana & $3,02,000$ & $8,51,000$ \\
\hline Guinea & 34,000 & 89,000 \\
\hline Guinea-Bissau & 17,000 & 44,000 \\
\hline Kenya & $\mathrm{I}, 83,000$ & $4,98,000$ \\
\hline Lesotho & 31,000 & 42,000 \\
\hline Liberia & 40,000 & $1,54,000$ \\
\hline Madagascar & $\mathrm{I}, 00,000$ & $3,01,000$ \\
\hline Malawi & 55,000 & $\mathrm{I}, \mathrm{I} 8,000$ \\
\hline Mali & $\mathrm{I}, 40,000$ & $4,05,000$ \\
\hline Mauritania & 34,000 & $\mathrm{I}, 03,000$ \\
\hline Mauritius & $\mathrm{I}, \mathrm{II}, 000$ & $2,33,000$ \\
\hline Mozambique & $1,33,000$ & $2,73,000$ \\
\hline
\end{tabular}


Table Continued...

\begin{tabular}{|c|c|c|}
\hline Country & 2000 & 2030 \\
\hline Namibia & 25,000 & 60,000 \\
\hline Niger & $1,08,000$ & $3,82,000$ \\
\hline Nigeria & $17,07,000$ & $48,35,000$ \\
\hline Rwanda & 30,000 & 77,000 \\
\hline Sao Tome-Principe & 1,000 & 2,000 \\
\hline Senegal & $1,43,000$ & $4,21,000$ \\
\hline Seychelles & 8,000 & 19,000 \\
\hline Sierra Leone & 65,000 & $\mathrm{I}, 78,000$ \\
\hline South Africa & $8,14,000$ & $12,86,000$ \\
\hline Swaziland & 13,000 & 21,000 \\
\hline Togo & 64,000 & $1,84,000$ \\
\hline Uganda & 98,000 & $3,28,000$ \\
\hline United Republic of Tanzania & $2,01,000$ & $6,05,000$ \\
\hline Zambia & 70,000 & $1,86,000$ \\
\hline Zimbabwe & $1,08,000$ & $2,65,000$ \\
\hline Total & $70,20,000$ & $18,234,000$ \\
\hline
\end{tabular}

\section{References}

1. Cho NH, Shaw JE, Karuranga S, et al. IDF Diabetes Atlas: Global estimates of diabetes prevalence for 2017 and projections for 2045 . Diabetes Res Clin Pract. 2018;138:271-281.

2. Pierre Lutgen. Diabetes, obesity and malaria: synergy or antagonism. Malaria world; 2016.

3. Munyangi J, Cornet-Vernet L, Idumbo M, et al. Artemisia annua and Artemisia afra tea infusions vs artesunate-amodiaquine (ASAQ) in treating Plasmodium falciparum malaria in a large scale, double blind, randomized clinical trial. Phytomedicine. 2019;57:49-56.

4. Munyangi J, Cornet-Vernet L, Idumbo M, et al. Effect of Artemisia annua and Artemisia afra tea infusions on schistosomiasis in a large clinical trial. Phytomedicine. 2018;51:233-240.

5. Chuipet Njamker GA. Etude préliminaire à l'utilisation de la phytothérapie de la tisane et de la limonade d'Artemisia. Thèse. Université des Montagnes: Cameroon; 2010-2011.

6. Udobre A, Edoho EJ, Eseyin O, et al. Effect of Artemisinin with Folic Acid on the Activities of Aspartate Amino Transferase, Alanine Amino Transferase and Alkaline Phosphatase in Rat. Asian Journal of Biochemistry. 2009;4(2):55-59.

7. Mojarad TB, Roghani M, Zare N. Effect of subchronic administration of aqueous Artemisia annua extract on $\alpha 1$ - adrenoceptor agonist-induced contraction of isolated aorta in rat. Iran Biochem J. 2005;9(2):57-62.

8. Issa IA, Hussen Bule M. Hypoglycemic Effect of Aqueous and Methanolic Extract of Artemisia afra on Alloxan Induced Diabetic Swiss Albino Mice. Evid Based Complement Alternat Med. 2015;2015:752486.

9. Younes K. Contribution à l'étude chimique et biologique de deux plantes médicinales de la région ouest d'Algérie : Artemisia arborescens L. et Cardaria draba (L.). Thèse de doctorat Université Abou Bekr BelkaidTlemcen; 2015.
10. Li Y, Zheng M, Zhai X, et al. Effect of-Gymnema Sylvestre Citrullus colocynthis and Artemisia absinthium on blood glucose and lipid profile in diabetic human. Acta Pol Pharm. 2015;72(5):981-985.

11. Sunmonu TO, Afolayan AJ. Evaluation of Antidiabetic Activity and Associated Toxicity of Artemisia afra Aqueous Extract in Wistar Rats. Evid Based Complement Alternat Med. 2013;2013:929074.

12. Daradka HM, Abas M, Jaffar M, et al. Antidiabetic effect of Artemisia absinthium extracts on alloxan-induced diabetic rats. Comparative Clinical Pathology. 2014;23(6):1733-1742.

13. Goud BJ. Methanol extracts of A. absinthium have a strong hypoglycemic and hepatoprotective activity. Int J Adv Pharmac Res. 2011;2:7.

14. Awad NE, Seida AA, El-Khayat Z, et al. Hypoglycemic Activity of Artemisia herba-alba (Asso.) used in Egyptian Traditional Medicine as Hypoglycemic Remedy. Appl Pharmaceutical Sci. 2012;2(3):30-39.

15. Allali A, Benmehdi H. Phytotherapy of Diabetes in West Algeria. Asian Journal of Chemistry. 2008;20(4):2701-2710.

16. Al-Kazraji SM, al-Shamaony LA, Twaij HA. Hypoglycemic effect of Artemisia herba alba in rabbits. J Ethnopharmacol. 1993;40(3):163-166.

17. Anaya-Eugenio GD, Rivero-Cruz I, Rivera-Chávez J, et al. Hypoglycemic properties of some preparations and compounds from Artemisia ludoviciana Nutt. J Ethnopharmacol. 2014;155(1):416-425.

18. Dabe N, Kefale A. Antidiabetic effects of Artemisia species: a systematic review. Anc Sci Life. 2017;36(4):175-181.

19. Al-Waili NS. Treatment of diabetes mellitus by Artemisia herba alba extract. Clin Exp Pharmacol Physiol. 1986;13(7):569-573.

20. Chen K, Hua H. Artemisinin and dihydroartemisinin promote $\beta$-cell apoptosis induced by palmitate via enhancing ER stress. Apoptosis; 2020.

21. Talitha van der Meulen Sharon Lee, Els Noordeloos. Artemether Does Not Turn Alpha Cells into Beta Cells. Cell Metabolism. 2018;27(1):218225.

22. Burk O, Arnold KA, Nussler AK, et al. Antimalarial artemisinin drugs induce cytochrome $\mathrm{P} 450$ and MDR1 expression by activation of xenosensors pregnane $\mathrm{X}$ receptor and constitutive androstane receptor. Mol Pharmacol. 2005;67(6):1954-1965.

23. Sara Asimus. Cytochrome P450 enzymes affected by artemisinin antimalarials-pharmacokinetic and pharmacogenetic aspects. Thesis Gothenberg, Sweden; 2008.

24. Song MK, Hwang IK, Rosenthal MJ. Antidiabetic actions of arachidonic acid and zinc in genetically diabetic Goto-Kakizaki rats. Metabolism. 2003;52(1):7-12.

25. Persaud SJ, Muller D, Belin VD, et al. The Role of Arachidonic Acid and Its Metabolites in Insulin Secretion from Human Islets of Langerhans. Diabetes. 2007;56(1):197-203.

26. Wu M, Wang X, Duan Q, et al. Arachidonic Acid Can Significantly Prevent Early Insulin Resistance Induced by a High-Fat Diet. Ann Nutr Metab. 2007;51(3):270-276.

27. Holman RT, Johnson SB, Gerrard J. Arachidonic acid deficiency in streptozotocin-induced diabetes. Proc Natl Acad Sci U S A. 1983;80(8):2375-2379.

28. Murat Kursat, Irfan Emre, Okkeş Yilmaz, et al. Phytochemical Contents of Five Artemisia Species. Notulae Scientia Biologicae. 2015;7(4):495499.

29. Pierre Lutgen. Are Artemisias the only plants containing arachidonic acid? Malaria world; 2016.

30. Liu W, Mao Y, Schoenborn J, et al. Whole blueberry protects pancreatic beta-cells in diet-induced obese mouse. Nutr Metab. 2019;16:34 
31. Johnson MH, de Mejia EG, Fan J, et al. Anthocyanins and proanthocyanidins from blueberry-blackberry fermented beverages. $\mathrm{Mol}$ Nutr Food Res. 2013;57(7):1182-1197.

32. Gonzalez-Abuin N, Binent M, Casanova-Marti A. Procyanidins and their healthy protective effects against type 2 diabetes. Curr Med Chem. 2015;22(1):39-50.

33. Muraki I, Imamura F. Fruit consumption and risk of type 2 diabetes: results from three prospective longitudinal cohort studies. BMJ. 2013;347:f5001.

34. Eddine LS, Redha OM, Ladjel S. Influence of solvent extraction on phenolic content, antioxidant and anti-inflammatory activities of aeria parts extract from Algerian Artemisia Herba-alba. J Pharmacy Res. 2016;10:58-64.

35. Mojarab M, Emami SA, Hassanzadeh-Khayyat M. Antioxidant activity of methanol extracts of different species of Artemisia from Iran. Pharmacologyonline. 2009;2:797-807.

36. Ghazanfar K, Ganai BS, Akber S, et al. Antidiabetic activity of Artemisia amygdalina in streptomycin induced diabetic rats. Biomed Res Int 2014;2014:185676.

37. Clemmensen C, Smajilovic S, Smith EP, et al. Oral 1-Arginine Stimulates GLP-1 Secretion to Improve Glucose Tolerance in Male Mice. Endocrinology. 2013;154(11):3978-3983.

38. Floyd JC, Fajans SS, Conn JW, et al. Stimulation of insulin secretion by amino acids. J Clin Invest. 1966;45(9):1487-1501.

39. Mohan IK, Das UN. Effect of L-Arginine.Nitric oxide on chemical induced diabetes mellitus. Free Radic Biol Med. 1998;25(7):757-765.

40. Ochkur O, Kovaleva AM. Amino acids composition of subgenus Artemisia herbs. Chemistry of Natural Compounds. 2013;49(3):589-591.

41. Nyström T, Ortsäter H, Huang Z, et al. Inorganic nitrite stimulates pancreatic islet blood flow and insulin secretion. Free Radic Biol Med. 2012;53(5):1017-1023.

42. Afolayan AJ, Sunmonmu TO. Artemisia afra Jacq. Ameliorates Oxidative Stress in the Pancreas of Streptozotocin-Induced Diabetic Wistar Rats. Biosci Biotechnol Biochem. 2011;75(11):2083-2086.

43. Kharroubi AT, Darwish HM, Akkawi MA. Total Antioxidant Status in Type 2 Diabetic Patients in Palestine. Journal of Diabetes Research. 2015;2015:461271.
44. Kharroubi T, Darwish HM, Akkawi MA. Total Antioxidant Status in Type 2 Diabetic Patients in Palestine. Journal of Diabetes Research. 2015;2015:461271

45. Xiao JQ, Liu WY, Sun HP, et al. Bioactivity-based analysis and chemical characterization of hypoglycemic and antioxidant components from Artemisia argyi. Bioorg Chem. 2019;92:103268.

46. Meng S, Cao J, Feng Q, et al. Roles of Chlorogenic Acid on Regulating Glucose and Lipids Metabolism: A Review. Evid Based Complement Alternat Med. 2013;2013:801457.

47. Fei Wang. Research Progress on Polysaccharides Hypoglycemic Mechanism and Therapeutic Potential. Chem \& Life Sci. 2011;9:57-62.

48. Wu J, Shi S, Wang H. Mechanisms underlying the effect of polysaccharides in the treatment of type 2 diabetes: A review. Carbohydr Polym. 2016;144:474-494.

49. Castellano JM, Guinda A, Delgado T, et al. Biochemical Basis of the Antidiabetic Activity of Oleanolic Acid and Related Pentacyclic Triterpene. Diabetes. 2013;62(6):1791-1799.

50. Nazaruk J, Borzym-Kluczyk M. The role of triterpenes in the management of diabetes mellitus and its complications. Phytochem Rev. 2015;14(4):675-690.

51. El Barky AR, Ali Hussein S. Saponins and their potential role in diabetes mellitus. Diabetes Management; 2012. 11 p.

52. Metwally NS, Mohamed AM. Chemical constituents of the Egyptian Plant Anabasis articulata (Forssk) Moq and its antidiabetic effects on rats with streptozotocin-induced diabetic hepatopathy. Diabetes Management. 2017;7(1).

53. Alkhateeb H, Al-duais M, Qnais E, et al. Plasma glucose lowering effect of thujone in streptozotocin-induced diabetic rats. Pharmacology OnLine. 2018;1:196-208.

54. Brisibe E, Magalhäes P, Ferreira JS. Nutritional characterisation and antioxidant capacity of different tissues of Artemisia annua L. Food Chemistry. 2009;115(4):1240-1246.

55. Chatterjee R, Zelnick L, Mukamal KJ, et al. Potassium Measures and Their Associations with Glucose and Diabetes Risk: The Multi-Ethnic Study of Atherosclerosis. PLoS One. 2016;11(6):e0157252. 